\title{
Solanum nigrum Line inhibits osteoclast differentiation and suppresses bone mineral density reduction in the ovariectomy-induced osteoporosis model
}

\author{
JAE-HYUN KIM* ${ }^{*}$, HWAJEONG SHIN ${ }^{*}$, MINSUN KIM, SANGWOO KIM, \\ KWANGCHAN SONG, HYUK-SANG JUNG and YOUNGJOO SOHN
}

Department of Anatomy, College of Korean Medicine, Kyung Hee University, Seoul 02-447, Republic of Korea

Received October 22, 2020; Accepted April 22, 2021

DOI: $10.3892 / \mathrm{mmr} .2021 .12246$

\begin{abstract}
Bone homeostasis is maintained by osteoclasts that absorb bone and osteoblasts that form bone tissue. Menopausal osteoporosis is a disease associated with aging and hormonal changes due to menopause causing abnormal activation of osteoclasts, resulting in a decrease in bone density. Existing treatments for osteoporosis have been reported to have serious side effects, such as jawbone necrosis and breast and uterine cancer; therefore, their use by patients is decreasing, whilst studies focusing on alternative treatments are increasingly popular. Solanum nigrum Line (SL) has been used as a medicinal plant that possesses several pharmacological effects, such as anti-inflammatory and hepatotoxic protective effects. To the best of our knowledge, however, its effects on osteoporosis and osteoclasts have not been demonstrated previously. In the present study, the anti-osteoporotic effect of SL was investigated using a postmenopausal model of osteoporosis in which Sprague-Dawley rat ovaries were extracted. In addition, the inhibitory effects on osteoclast differentiation and function of SL was confirmed using an osteoclast model treated with receptor activator of $\mathrm{NF}-\kappa \mathrm{B}$ ligand (RANKL) on murine RAW 264.7 macrophages. In vivo experiments showed that SL reduced the decrease in bone mineral density and improved changes in the morphological index of bone microstructure, such as trabecular number and separation. In addition, the number of tartrate resistant acid phosphatase-positive cells in the femur and the expression levels of nuclear factor of activated
\end{abstract}

Correspondence to: Professor Youngjoo Sohn or Professor Hyuk-Sang Jung, Department of Anatomy, College of Korean Medicine, Kyung Hee University, 753-ho, SPACE 21, 26-6, Kyungheedae-ro, Dongdaemun, Seoul 02-447, Republic of Korea

E-mail: youngjoos@khu.ac.kr

E-mail: jhs@khu.ac.kr

*Contributed equally

Key words: Solanum nigrum Line, ovariectomy-induced osteoporosis, nuclear factor of activated T-cells cytoplasmic 1, c-Fos, osteoclasts, receptor activator of $\mathrm{NF}-\kappa \mathrm{B}$ ligand
T-cells cytoplasmic 1 (NFATc1) and cathepsin K protein were inhibited. In vitro, SL suppressed RANKL-induced osteoclast differentiation and bone resorption ability; this was mediated by NFATc1/c-Fos, a key transcription factor involved in osteoclast differentiation, ultimately inhibiting expression of various osteoclast-associated genes. These experimental results show that SL may be an alternative treatment for osteoporosis caused by abnormal activation of osteoclasts in the future.

\section{Introduction}

Osteoporosis is a systemic skeletal disease characterized by a decrease in bone density (1). Bone homeostasis is maintained by osteoclasts, which absorb bone, and osteoblasts, which form bone (2). This homeostasis can be unbalanced by various causes, such as menopause, aging and steroidal side effects (3). Among these, hormonal changes due to menopause are the cause of abnormal osteoclast activity. Various drugs, such as bisphosphonates, parathyroid hormone, denosumab and selective estrogen receptor modulator, have been used to treat osteoporosis (4), but these drugs are not suitable for long-term treatment due to serious side effects, including mandibular necrosis and cardiovascular disease (5). Therefore, research and development of a natural-based treatment for osteoporosis with fewer and less severe side effects is required.

Solanum nigrum Line (SL) has been used as a medicinal plant in East Asian countries, such as Korea, Japan and China. SL is the above-ground part of Solanum nigrum Linné (Solanaceae) and has traditionally been used to treat conditions associated with inflammatory disease, such as boils, cancer and chronic bronchitis (6). A previous study reported that SL methanol extract inhibits osteoclast differentiation (7). To the best of our knowledge, however, the effects of ethanol extract, mechanism of osteoclast inhibition and effects of SL in osteoporosis have not been identified. In addition, inflammatory conditions and aging are known to increase the risk of developing osteoporosis $(8,9)$. Various natural herbs showing anti-inflammatory effects have been shown to be effective in treating osteoporosis $(10,11)$. In previous studies, SL has been shown to have anti-inflammatory effects $(12,13)$. Therefore, SL may serve as a potential treatment for postmenopausal osteoporosis by suppressing abnormal osteoclast activity. 
Osteoclasts are multinucleated giant cells derived from hematopoietic progenitors (14). Receptor activator of $N F-\kappa B$ ligand (RANKL) is a member of the tumor necrosis factor (TNF) superfamily and is a cytokine that serves an important role in osteoclast differentiation and mature osteoclast activity (15). When RANKL binds to RANK, TNF receptor-associated factor 6 expression is upregulated, leading to activation of downstream signaling molecules, such as MAPK and NF- $\kappa$ B. Thereafter, c-Fos and nuclear factor of activated T-cells, cytoplasmic 1 (NFATc1), which are key transcription factors involved in osteoclast differentiation, are sequentially expressed (2). Finally, these factors induce expression of factors associated with osteoclast differentiation and bone resorption, such as tartrate-resistant acid phosphatase (TRAP), cathepsin K (CTsK), matrix metallopeptidase-9 (MMP-9) and carbonic anhydrase 2 (CA2) (16).

In the present study, the anti-osteoporotic effects of SL were investigated using an ovariectomy (OVX)-induced osteoporosis model, which is the most commonly used model of postmenopausal osteoporosis (11,17-19). In addition, to confirm the effects of SL on osteoclast differentiation, its ability to inhibit osteoclast differentiation and the underlying mechanism were assessed using a RANKL-induced osteoclast model.

\section{Materials and methods}

Reagents. SL was purchased from Omniherb (Dongwoodang Pharmacy Co., Ltd.); $17 \beta$-estradiol $\left(\mathrm{E}_{2}\right)$, TRAP staining kit, chlorogenic and caffeic acid, quercetin and protease and phosphatase inhibitor cocktail were purchased from Sigma-Aldrich (Merck KGaA). Minimum Essential Medium Eagle, $\alpha$-Modification ( $\alpha$-MEM), FBS, penicillin/streptomycin (P/S) and Dulbecco's PBS (DPBS) were obtained from Gibco (Thermo Fisher Scientific, Inc.). DMEM was purchased from Welgene, Inc. RANKL was obtained from PeproTech, Inc. Anti-NFATc1 (cat. no. 556602) was purchased from BD Pharmingen (BD Biosciences; used for western blotting) and anti-c-Fos (cat. no. sc-447), anti-CTsK (cat. no. sc-48353), anti-NFATc1 (cat. no. sc-7294; used for immunohistochemistry), anti- $\beta$-actin (cat. no. sc-8432) and ECL solution were obtained from Santa Cruz Biotechnology, Inc. The SuperScript ${ }^{\circledR}$ IV reverse transcriptase (RT) kit and SYBR Green were purchased from Invitrogen (Thermo Fisher Scientific, Inc.) and Taq polymerase was purchased from MGmed. PCR primers were obtained from GenoTech Corp. All reagents used in cell experiments were analytical grade.

Preparation of SL. SL was verified by Professor Yungmin $\mathrm{Bu}$ at the Herbology Laboratory, College of Korean Medicine, Kyunghee University (Seoul, South Korea). The plant specimens were stored in the plant storage cabinet of the Anatomy Laboratory, College of Korean Medicine, Kyunghee University. SL was extracted by immersion in $80 \%$ ethanol (Et-OH) for 2 weeks at $4^{\circ} \mathrm{C}$. Bottles containing SL and Et-OH was shaken at the same time every day. Et-OH in the solution was removed using a concentrator, and the extracts were lyophilized at $-20^{\circ} \mathrm{C}$ for $48 \mathrm{~h}$ to obtain a powder (yield, $13.88 \%$ ). The extracts were stored in a cryogenic refrigerator at $-80^{\circ} \mathrm{C}$ until required and diluted in DMSO $(100 \mathrm{mg} / \mathrm{ml})$ for use in experiments.
Animals and OVX-induced osteoporosis in Sprague Dawley $(S D)$ rats. The in vivo experiments were approved by the Kyunghee University Institutional Animal Care and Use Committee [approval no. KHUASP(SE)-17-052]. A total of 40 12-week-old female SD rats (weight, 230-250 g) were purchased from Koatech. The animals were housed at $22 \pm 2{ }^{\circ} \mathrm{C}$ with $55 \pm 10 \%$ humidity and a 12 -h light/dark cycle. Rats were provided ad libitum access to food and water and allowed to acclimatize for 1 week. Body weight was measured weekly. Humane end points were as follows: i) weight loss $\geq 20 \%$ compared with other rats of the same age; ii) difficultly ingesting food or water due to uncomfortable walking; iii) difficulty maintaining a normal posture due to low energy; iv) unconsciousness or lack of reaction to external stimuli; and v) severe infection, laceration and bleeding at the surgical site.

In order to induce osteoporosis, 32 SD rats were deeply anesthetized using $\mathrm{O}_{2}$ diluted with $5 \%$ isoflurane. After removing the hair from the surgical site, the epidermis and muscles were incised and both ovaries were removed. Additionally, eight SD rats underwent the same procedure but the ovaries were not removed (sham operation). During surgery, the concentration of isoflurane was maintained at 2-3\%. No rats died during surgery. In order to prevent infection following surgery, gentamycin ( $4 \mathrm{mg} / \mathrm{kg}$ ) was given intraperitoneally for 3 days. After 1 week stabilization, administration of distilled water (DW), SL and $\mathrm{E}_{2}$ (positive control) was initiated. Experimental groups were as follows: i) Sham, mock surgery then daily oral administration of DW; ii) OVX, OVX surgery then daily oral administration of DW; iii) $\mathrm{E}_{2}$, OVX surgery then daily oral administration of $100 \mu \mathrm{g} / \mathrm{kg} \mathrm{E} \mathrm{E}_{2}$; iv) SL-low, OVX surgery then daily oral administration of $50 \mathrm{mg} / \mathrm{kg} \mathrm{SL}$; and v) SL-high, OVX surgery then daily oral administration of $100 \mathrm{mg} / \mathrm{kg}$ SL. The dosage of SL was calculated based on the following criteria: In Korean medicine, an adult human dose of $60 \mathrm{~kg}$ is a daily dose of SL of $8 \mathrm{~g}$. Given that the SL used in the present experiment was lyophilized powder, and the yield was $13.88 \%, 18.5 \mathrm{mg} / \mathrm{kg}$ was equivalent to the recommended adult dose. In addition, rats generally metabolize drugs faster than humans (20). SL-low group were administered $\sim 2$ times the calculated amount and the SL-high group was administered $\sim 5$ times the calculated amount. After the 8-week dosing period, SD rats were sacrificed via cervical dislocation after collecting $10 \mathrm{ml}$ blood via cardiac puncture under deep anesthesia with $\mathrm{O}_{2}$ diluted with $5 \%$ isoflurane. In order to determine the success of OVX surgery, the ovaries were collected and weighed and the right femur was extracted for micro-computed tomography (CT) analysis and histological examination.

Micro-CT analysis. In order to confirm the anti-osteoporotic effects of SL, changes in bone microstructure of the femoral head of the right femur were scanned using a high-resolution cone beam micro-CT system (SkyScan1176; Bruker Corporation) with an aluminum filter of $0.5 \mathrm{~mm}$, source set at $50 \mathrm{kV} / 200 \mu \mathrm{A}$ and $8.9 \mu \mathrm{m}$ isotropic resolution. Starting with the growth plate of the femoral head, 200 slides were taken and visualized using Data Viewer software (Skyscan version 1.6.10.1; Bruker Corporation). Bone microstructure indexes, such as bone mineral density (BMD), bone volume fraction (BV/TV), trabecular number (Tb.N) and trabecular separation (Tb.Sp) were measured using Skyscan. 
Serum analysis. Blood extracted at the time of sacrifice was stored at room temperature for $30 \mathrm{~min}$. Then, the serum was separated by centrifugation at $14,310 \mathrm{x}$ g for $20 \mathrm{~min}$ at $4^{\circ} \mathrm{C}$. In order to measure TRAP activity in the serum, $50 \mu \mathrm{l}$ serum and $50 \mu \mathrm{l}$ TRAP solution (4.93 $\mathrm{mg}$ para-nitrophenyl phosphate $+850 \mu 10.5 \mathrm{M}$ acetate solution $+150 \mu \mathrm{l}$ tartrate solution) were reacted at $37^{\circ} \mathrm{C}$ for $1 \mathrm{~h}$. The reaction was terminated with $50 \mu 10.5 \mathrm{M} \mathrm{NaOH}$ and TRAP activity was measured at an absorbance of $405 \mathrm{~nm}$ using an ELISA reader (Versamax; Molecular Devices, LLC).

Histological examination. The femur was fixed for 2 days using $10 \%(\mathrm{v} / \mathrm{v})$ neutral buffered formalin at room temperature. The tissue was demineralized for 8 weeks using a solution of EDTA-2Na at room temperature. The demineralized tissue was dehydrated using Et-OH (at gradient concentration of 70 , 80,90 and $100 \%$ for 5 min per concentration), cleared with xylene and embedded in paraffin. The embedded tissue was sectioned to a thickness of $5 \mu \mathrm{m}$ using a rotary microtome. Histomorphological changes were assessed by $7 \%$ hematoxylin and $1 \%$ eosin (H\&E) staining at room temperature. Moreover, to measure the number of osteoclasts in the femur, a TRAP staining kit was used according to the manufacturer's protocol. For immunohistochemical (IHC) staining, tissue antigens were retrieved with proteinase $\mathrm{K}$ (Thermo Fisher Scientific, Inc.) at $37^{\circ} \mathrm{C}$ for $1 \mathrm{~h}$. Endogenous peroxidase was blocked using $3 \% \mathrm{H}_{2} \mathrm{O}_{2}$ diluted in methanol at room temperature for $30 \mathrm{~min}$. Normal serum (Gibco; Thermo Fisher Scientific, Inc.) was added at room temperature for $1 \mathrm{~h}$ to block the binding of non-specific proteins. Antibodies were diluted in tris-buffered saline containing $0.5 \%$ bovine serum albumin and reacted at $4^{\circ} \mathrm{C}$ overnight with anti-NFATc1 (1:100; cat. no. sc-7294) and anti-CTsK (1:100; cat. no. sc-48353). Subsequently, the secondary antibody (1:100; rabbit; cat. no. BA-1000) was added at room temperature for $1 \mathrm{~h}$, and then VECTASTAIN Elite ABC kit (cat. no. PK-6100; both Vector Laboratories, Inc.; Maravai LifeSciences) was used according to the manufacturer's instructions. The tissue was reacted with 3,3'-diaminobenzidine (Vector Laboratories, Inc.; Maravai LifeSciences) at room temperature for $5 \mathrm{~min}$ and counterstained with $7 \%$ hematoxylin for $30 \mathrm{sec}$ at room temperature. Dyed tissues were observed using a light microscope (magnification, x100) and imaged using a DP73 camera (Olympus Corporation). The trabecular area and positive cells for each indicator were assessed using ImageJ software (version 1.51j8; National Institutes of Health).

Cell culture and viability assay. RAW 264.7 cells were purchased from the Korean Cell Line Bank (cat no. 40071; lot no. 41484). RAW 264.7 cells were cultured in DMEM containing $10 \% \mathrm{FBS}$ and $1 \% \mathrm{P} / \mathrm{S}$ and sub-cultured every 2 days. MC3T3-E1 Subclone 4 cells were purchased from the American Type Culture Collection (cat no. CRL-2593). MC3T3-E1 cells were cultured in $\alpha$-MEM without ascorbic acid containing $10 \% \mathrm{FBS}$ and $1 \% \mathrm{P} / \mathrm{S}$, and sub-cultured every 3 days. Both cell lines were maintained in a humidified incubator at $37^{\circ} \mathrm{C}, 95 \%$ humidity and $5 \% \mathrm{CO}_{2}$. In order to measure the cytotoxicity of SL, RAW 264.7 cells were seeded in 96-well plates at a density of $5 \times 10^{3}$ cells/well and stabilized for 1 day. In addition, in order to investigate the toxicity of
SL to osteoclasts, RAW 264.7 cells were stimulated for 5 days using $100 \mathrm{ng} / \mathrm{ml} \mathrm{RANKL}$ and 5, 10, 20 or $40 \mu \mathrm{g} / \mathrm{ml} \mathrm{SL}$ in a humidified incubator at $37^{\circ} \mathrm{C}$. To determine the effect of SL on cell viability, cells were treated with SL for $24 \mathrm{~h}$ and $20 \mu \mathrm{l}$ Cell Counting Kit-8 (Dojindo Molecular Technologies, Inc.) solution was subsequently added for $2 \mathrm{~h}$. The absorbance in each well was measured at a wavelength of $450 \mathrm{~nm}$ using a microplate reader. SL was considered to be toxic when cell survival rate was $\leq 90 \%$ compared with untreated cells. In order to measure the effect of SL on cell necrosis, RAW 264.7 cells were seeded in 96-well plates at a density of $5 \times 10^{3}$ cells/well and stabilized for 1 day. Thereafter, cells were treated with 5, 10,20 or $40 \mu \mathrm{g} / \mathrm{ml} \mathrm{SL}$ for $24 \mathrm{~h}$ in a humidified incubator at $37^{\circ} \mathrm{C}$, and cell necrosis rate was measured using a lactate dehydrogenase (LDH) assay kit (Dojindo Molecular Technologies, Inc.) (21), according to the manufacturer's protocol. LDH is released from cells upon cell death, thus LDH levels in the culture medium were used as an indicator of cell death (21).

TRAP staining and pit formation assays. TRAP is an osteoclast-specific marker and is used to determine whether osteoclasts are differentiated (22). In order to induce osteoclast differentiation, RAW 264.7 cells were cultured in $\alpha$-MEM containing $10 \% \mathrm{FBS}$ and $1 \% \mathrm{P} / \mathrm{S}\left(5 \times 10^{3}\right.$ cells/well $)$ in a humidified incubator at $37^{\circ} \mathrm{C}$ with $5 \% \mathrm{CO}_{2}$ and stabilized for 1 day. Subsequently, the cells were exposed to $100 \mathrm{ng} / \mathrm{ml} \mathrm{RANKL}$ and $5,10,20$ or $40 \mu \mathrm{g} / \mathrm{ml} \mathrm{SL}$ for 5 days. The medium was replaced with fresh medium every 2 days. After osteoclast differentiation was completed, cells were fixed with $10 \%$ formalin solution at room temperature for $10 \mathrm{~min}$ and stained using the TRAP staining kit as aforementioned. In order to test the effects of SL on osteoclast ability to absorb bone, RAW 264.7 cells were cultured in hydroxyapatite-coated plates (Corning, Inc.) with 5, 10, 20 or $40 \mu \mathrm{g} / \mathrm{ml} \mathrm{SL}$ in a humidified incubator at $37^{\circ} \mathrm{C}$ for 5 days. The medium was replaced with fresh medium every 2 days. Thereafter, the cells were lysed with $4 \% \mathrm{NaClO}$, washed three times with DPBS and dried completely. Plates were imaged using a light microscope at x100 magnification in five random fields of view per well. The absorbed area is expressed as a percentage of the total area.

Actin ring formation assay. In order to measure filamentous (F-)actin ring formation, RAW 264.7 cells were cultured in $\alpha$-MEM containing $10 \% \mathrm{FBS}$ and $1 \% \mathrm{P} / \mathrm{S}\left(5 \times 10^{3}\right.$ cells/well) and stabilized for 1 day. Subsequently, the cells were exposed to $100 \mathrm{ng} / \mathrm{ml}$ RANKL and medium containing 5, 10, 20 or $40 \mu \mathrm{g} / \mathrm{ml} \mathrm{SL}$ for 5 days. The differentiated cells were fixed with $4 \%$ paraformaldehyde at room temperature for $20 \mathrm{~min}$ and permeabilized with PBS containing $0.1 \%$ Triton X-100 at room temperature for $5 \mathrm{~min}$. Subsequently, the cells were stained with $200 \mu 1100 \mathrm{nM}$ Acti-Stain ${ }^{\mathrm{TM}}$ Fluorescent Phalloidins for $30 \mathrm{~min}$ at room temperature (cat. no. PHDG1; Cytoskeleton, Inc.) and the nuclei were counterstained with $200 \mu 1100 \mathrm{nM}$ DAPI in PBS for $30 \mathrm{sec}$ at room temperature (Sigma-Aldrich; Merck KGaA). The F-actin formation was imaged using an immunofluorescence microscope at x100 magnification (Celena; Logos Biosystems).

Western blotting. In order to determine protein expression following SL treatment, RAW 264.7 cells were seeded in a 
Table I. Primers used for reverse transcription-quantitative PCR.

\begin{tabular}{|c|c|c|c|c|}
\hline Gene & Sequence, $5^{\prime}-3^{\prime}$ & Accession number & $\mathrm{Tm},{ }^{\circ} \mathrm{C}$ & Base pair \\
\hline $\begin{array}{l}\text { NFATc1 } \\
(\text { Nfatcl })\end{array}$ & $\begin{array}{l}\text { Forward: TGC TCC TCC TCC TGC TGC TC } \\
\text { Reverse: CGT CTT CCA CCT CCA CGT CG }\end{array}$ & NM_198429.2 & 58 & 480 \\
\hline $\begin{array}{l}\text { c-Fos } \\
(F o s)\end{array}$ & $\begin{array}{l}\text { Forward: ATG GGC TCT CCT GTC AAC AC } \\
\text { Reverse: GGC TGC CAA AAT AAA CTC CA }\end{array}$ & NM_010234.3 & 55 & 480 \\
\hline $\begin{array}{l}\text { TRAP } \\
(\text { Acp5) }\end{array}$ & $\begin{array}{l}\text { Forward: ACT TCC CCA GCC CTT ACT ACC G } \\
\text { Reverse: TCA GCA CAT AGC CCA CAC CG }\end{array}$ & NM_007388.3 & 58 & 381 \\
\hline $\begin{array}{l}\text { RANK } \\
\text { (Tnfrsfl1a) }\end{array}$ & $\begin{array}{l}\text { Forward: AAA CCT TGG ACC AAC TGC AC } \\
\text { Reverse: ACC ATC TTC TCC TCC CHA GT }\end{array}$ & NM_009399.3 & 53 & 377 \\
\hline $\begin{array}{l}\text { CTsK } \\
(\text { Ctsk })\end{array}$ & $\begin{array}{l}\text { Forward: AGG CGG CTA TAT GAC CAC TG } \\
\text { Reverse: CCG AGC CAA GAG AGC ATA TC }\end{array}$ & NM_007802.4 & 58 & 403 \\
\hline $\begin{array}{l}\text { CA2 } \\
(\mathrm{Ca} 2)\end{array}$ & $\begin{array}{l}\text { Forward: CTC TCA GGA CAA TGC AGT GCT GA } \\
\text { Reverse: ATC CAG GTC ACA CAT TCC AGC A }\end{array}$ & NM_001357334.1 & 58 & 411 \\
\hline $\begin{array}{l}\text { MMP-9 } \\
(\text { Mmp9) }\end{array}$ & $\begin{array}{l}\text { Forward: CGA CTT TTG TGG TCT TCC CC } \\
\text { Reverse: TGA AGG TTT GGA ATC GAC CC }\end{array}$ & NM_013599.4 & 58 & 258 \\
\hline $\begin{array}{l}\text { ATP6v0d2 } \\
(\text { Atp6v0d2) }\end{array}$ & $\begin{array}{l}\text { Forward: ATG GGG CCT TGC AAA AGA AAT CTG } \\
\text { Reverse: CGA CAG CGT CAA ACA AAG GCT TGT A }\end{array}$ & NM_175406.3 & 58 & 504 \\
\hline $\begin{array}{l}\text { OSCAR } \\
(\text { Oscar })\end{array}$ & $\begin{array}{l}\text { Forward: CTG CTG GTA ACG GAT CAG CTC CCC AGA } \\
\text { Reverse: CCA AGG AGC CAG AAC CTT CGA AAC T }\end{array}$ & NM_001290377.1 & 53 & 310 \\
\hline $\begin{array}{l}\text { Actin } \\
(A c t b)\end{array}$ & $\begin{array}{l}\text { Forward: TTC TAC AAT GAG CTG CGT GT } \\
\text { Reverse: CTC ATA GCT CTT CTC CAG GG }\end{array}$ & NM_007393 & 58 & 456 \\
\hline
\end{tabular}

NFATc1, nuclear factor of activated T cells c1; TRAP, tartrate-resistant acid phosphatase; RANK, receptor activator of NF- $\mathrm{B}$; CTsK, cathepsin K; CA2, carbonic anhydrase II; OSCAR, osteoclast-associated immunoglobulin-like receptor; ATP6v0d2, ATPase $\mathrm{H}^{+}$transporting V0 subunit d2.

60-mm dish at a density of $5 \times 10^{5}$ cells/well and stabilized for 1 day. The cells were treated with $100 \mathrm{ng} / \mathrm{ml}$ RANKL and $5,10,20$ or $40 \mu \mathrm{g} / \mathrm{ml} \mathrm{SL}$ in a humidified incubator at $37^{\circ} \mathrm{C}$ for 1 day. In order to extract total and nuclear protein, the cells were washed three times using DPBS, and lysed using RIPA buffer and NE-PER ${ }^{\mathrm{TM}}$ nuclear and cytoplasmic extraction reagents (Thermo Fisher Scientific, Inc.). The lysates were maintained on ice for $30 \mathrm{~min}$ and centrifuged at $58,440 \mathrm{x} \mathrm{g}$ for $20 \mathrm{~min}$ at $4^{\circ} \mathrm{C}$. Protein concentration was quantified using a bicinchoninic acid assay kit (Sigma-Aldrich; Merck KGaA). Equal quantities (30 $\mu \mathrm{g})$ of protein were loaded on a $10 \%$ SDS-gel, and resolved using SDS-PAGE at $100 \mathrm{~V}$ for $1.5 \mathrm{~h}$. The resolved proteins were transferred to nitrocellulose membranes (Whatman plc; Cytiva) at $100 \mathrm{~V}$ for $1 \mathrm{~h}$. Non-specific proteins in the membrane were blocked using TBST $(0.5 \%$ Tween-20) and 5\% skimmed milk for $1 \mathrm{~h}$ at room temperature. The membrane was reacted with primary antibodies against NFATc1 (1:1,000; cat. no. 556602), c-Fos (1:200; cat. no. sc-447) and $\beta$-actin (1:500; cat. no. sc-8432) at $4^{\circ} \mathrm{C}$ overnight. Subsequently, the membranes were incubated with a horseradish peroxidase-conjugated secondary antibody for $1 \mathrm{~h}$ at room temperature (1:10,000; mouse; cat. no. 115-035-062; Jackson ImmunoResearch Laboratories, Inc.), and the expression of each indicator was visualized using ECL solution. The expression of each indicator was measured using ImageJ version $1.51 \mathrm{j} 8$ (National Institutes of Health) and normalized to $\beta$-actin.
RT-semi-quantitative PCR. In order to measure mRNA expression following SL treatment, RAW 264.7 cells were seeded in 6-well-plates at a density $2 \times 10^{4}$ cells/well and stabilized for 1 day. The cells were exposed to $100 \mathrm{ng} / \mathrm{ml} \mathrm{RANKL}$ and 5, 10,20 or $40 \mu \mathrm{g} / \mathrm{ml} \mathrm{SL}$ in a humidified incubator at $37^{\circ} \mathrm{C}$ for 4 days. Thereafter, the cells were washed 3 times using DPBS and were lysed using TRIzol ${ }^{\circledR}$ reagent (Takara Bio, Inc.). The extracted mRNA was quantified using NanoDrop (Thermo Fisher Scientific, Inc.), and $2 \mu \mathrm{g}$ RNA was reverse transcribed into cDNA using the SuperScript ${ }^{\circledR}$ IV RT kit according to the manufacturer's protocol. cDNA was amplified using Taq polymerase and target primers in a C1000 Touch $^{\mathrm{TM}}$ Thermal Cycler (Bio-Rad Laboratories, Inc.). The following thermocycling conditions were used for qPCR: $22-40$ cycles of $30 \mathrm{sec}$ at $94^{\circ} \mathrm{C}$ (denaturation); $30 \mathrm{sec}$ at $53-58^{\circ} \mathrm{C}$ (annealing); and $30 \mathrm{sec}$ at $72^{\circ} \mathrm{C}$ (extension). The target primer sequence and annealing temperature are listed in Table I. The PCR reactants were electrophoresed on SYBR-Green-dyed $2 \%$ agarose gels diluted in $1 \%$ Tris acetate-EDTA buffer. The expression of each mRNA was measured using ImageJ software (version 1.51j8; National Institutes of Health) with $\beta$-actin as the loading control.

Alizarin red Staining. In order to induce osteoblast differentiation, MC3T3-E1 cells were cultured in $\alpha$-MEM without ascorbic acid containing $10 \% \mathrm{FBS}$ and $1 \% \mathrm{P} / \mathrm{S}\left(1.5 \times 10^{4}\right.$ cells/24-well plate) in a humidified incubator at $37^{\circ} \mathrm{C}$ and stabilized for 1 day. Subsequently, the cells were exposed to $25 \mu \mathrm{g} / \mathrm{ml}$ ascorbic acid, 
A
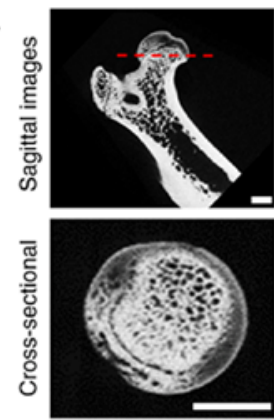

Sham

B

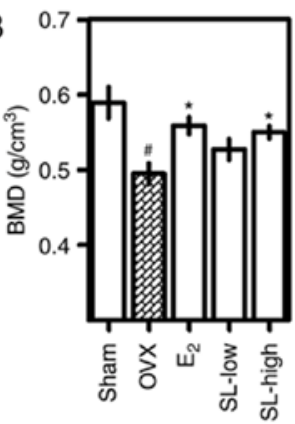

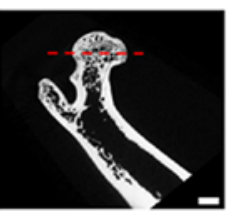

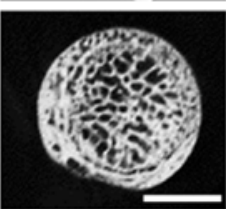

OVX
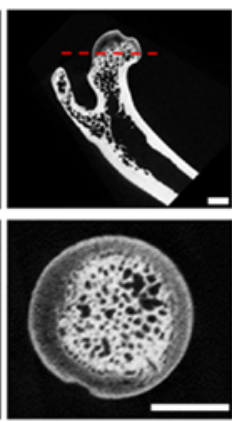

$\mathrm{OVX}+\mathrm{E}_{2}$

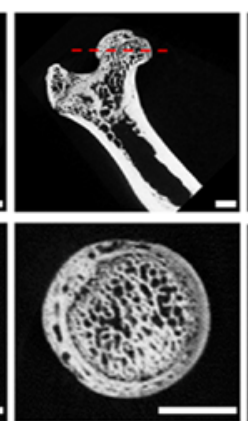

OVX+SL-low

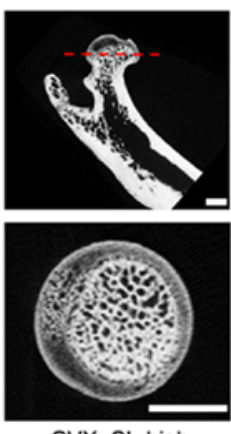

OVX+SL-high
$\mathrm{F}$

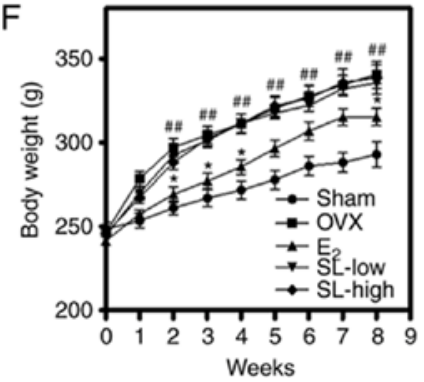

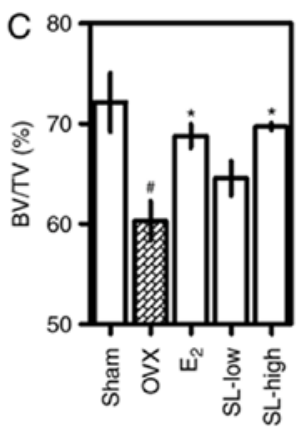

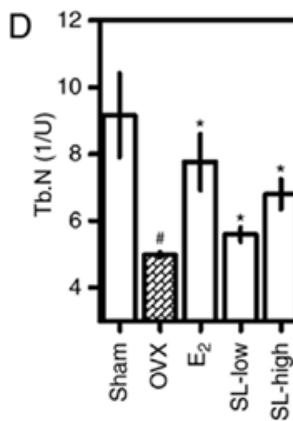

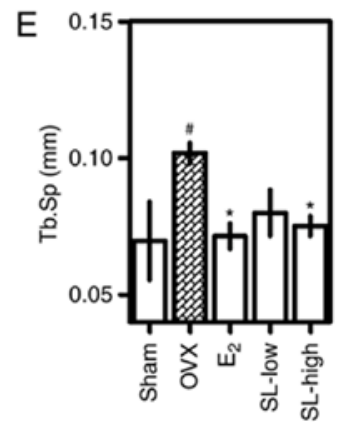
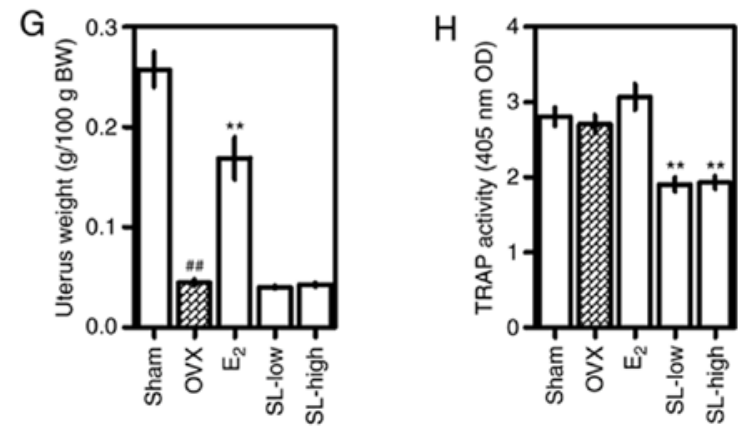

Figure 1. Effect of SL on bone density in an OVX-induced osteoporosis model. Osteoporosis was induced in Sprague Dawley rats (12-weeks-old) via OVX. Rats were then treated with SL or $\mathrm{E}_{2}$ for 8 weeks. (A) Changes in the bone microstructure in the femoral tissue induced by OVX were imaged using micro-CT (scale bar, $2 \mathrm{~mm}$ ). (B) BMD, (C) BV/TV, (D) Tb.N and (E) Tb.Sp was analyzed using micro-CT. (F) Body weight was measured weekly. (G) Uterine weight was measured after sacrifice. (H) TRAP activity in serum was measured using ELISA. The results are expressed as the mean $\pm \mathrm{SEM}$ ( $\mathrm{n}=8$ ). ${ }^{\#} \mathrm{P}<0.05$ and ${ }^{\# \prime} \mathrm{P}<0.01 \mathrm{vs}$. sham; ${ }^{*} \mathrm{P}<0.05$ and ${ }^{* *} \mathrm{P}<0.01$ vs. OVX. OVX, ovariectomy; SL, Solanum nigrum Line; $\mathrm{E}_{2}$, 17ß-estradiol; CT, computed tomography; BMD, bone mineral density; BV/TV, bone volume/total volume; Tb.N, trabecular number; Tb.Sp, trabecular separation; TRAP, tartrate-resistant acid phosphatase; OD, optical density; BW, body weight.

$10 \mathrm{mM} \beta$-glycerophosphate and medium containing SL $(5,10$, $20 \mu \mathrm{g} / \mathrm{ml}$ ) in a humidified incubator at $37^{\circ} \mathrm{C}$ for 14 days. The medium was replaced with fresh culture medium every 3 days. After osteoblast differentiation was completed, calcified nodules in the plate were fixed with $80 \% \mathrm{Et}-\mathrm{OH}$ at $4^{\circ} \mathrm{C}$ for $1 \mathrm{~h}$ and stained using $0.1 \%$ alizarin red $\mathrm{S}$ solution (Duksan Pharmaceutical Co., Ltd.) at room temperature for $5 \mathrm{~min}$. The nodules were imaged using a camera and light microscope (magnification, x100). The stained dye was extracted using $10 \mathrm{mM}$ sodium phosphate ( $\mathrm{pH} 7.0$ ) diluted in $10 \%$ cetylpyridinium chloride and measured at absorbance at $405 \mathrm{~nm}$.

High-performance liquid chromatography (HPLC) analysis. Chlorogenic acid, caffeic acid and quercetin are active ingredients of SL $(23,24)$. In order to analyze the SL extracts, HPLC was performed. Absorbance was measured using a UV detector (2996 Waters 2695). Xbridge C18 (250.0x4.6 mm, $5 \mu \mathrm{m})$ was used as the column and proceeded at $30^{\circ} \mathrm{C}$ for $50 \mathrm{~min}$ at a flow rate of $1 \mathrm{ml} / \mathrm{min}$. Samples were injected in a volume of $10 \mu \mathrm{l}$.
As the mobile phase, (A) acetonitrile and (B) $\mathrm{H}_{2} \mathrm{O}$ diluted with $1 \%$ acetic acid were used (ratio, 9:1). Ingredients were detected at an absorbance of $280 \mathrm{~nm}$.

Statistical analysis. Data are presented as the mean \pm SEM $(n \geq 3)$ and were analyzed using GraphPad prism software (version 5.01; GraphPad Software Inc.). Comparisons between groups were performed using one-way ANOVA with post hoc Tukey's test. $\mathrm{P}<0.05$ was considered to indicate a statistically significant difference.

\section{Results}

SL decreases loss of bone density and changes in bone microstructure caused by $O V X$. In order to investigate the effects of SL on menopausal osteoporosis, SL was administered following removal of both ovaries. Changes in bone density of the femoral head were measured using micro-CT (Fig. 1A). The density of trabecular bone in the femoral head was lower 

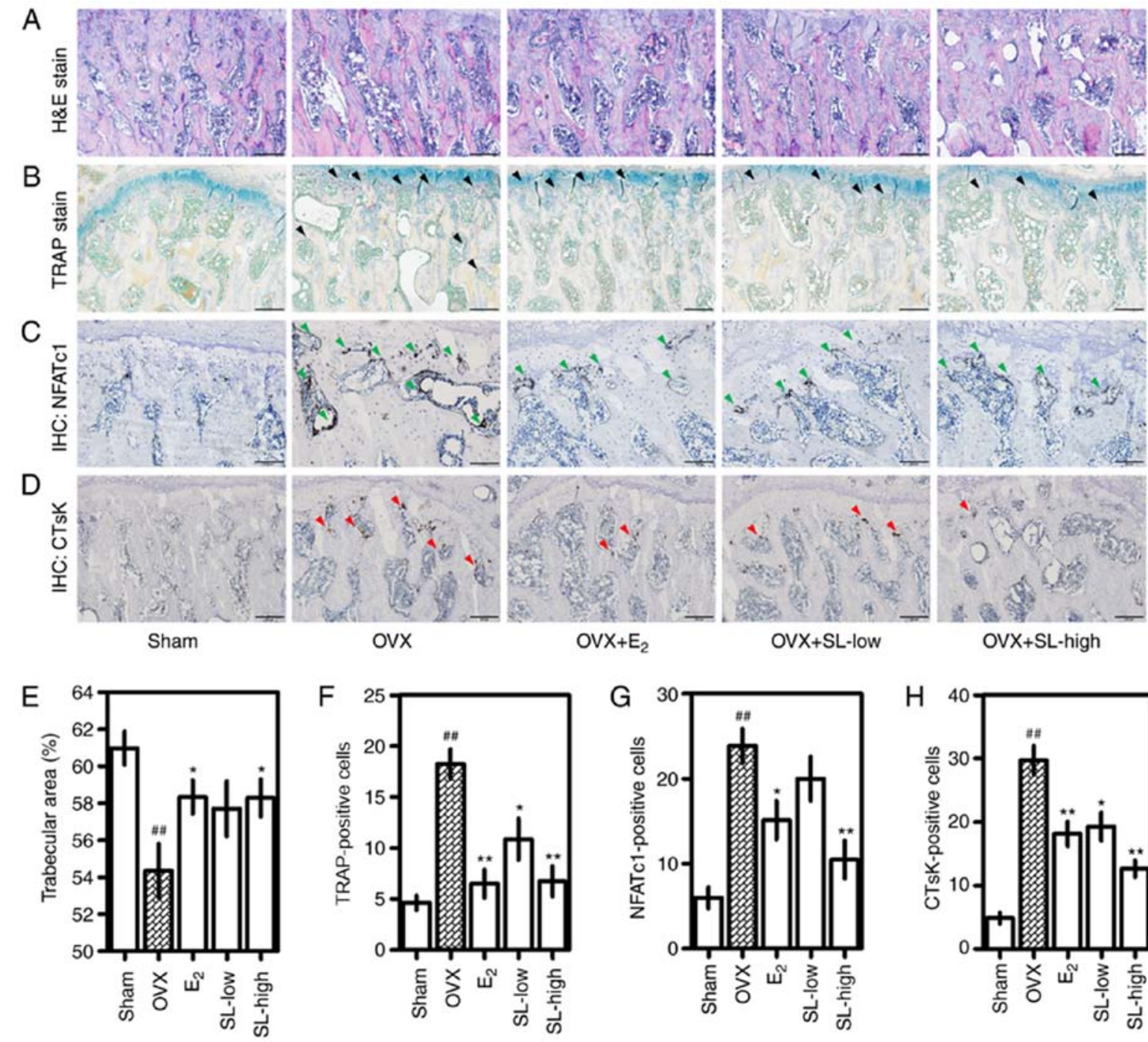

OVX+SL-IOW

OVX+SL-high
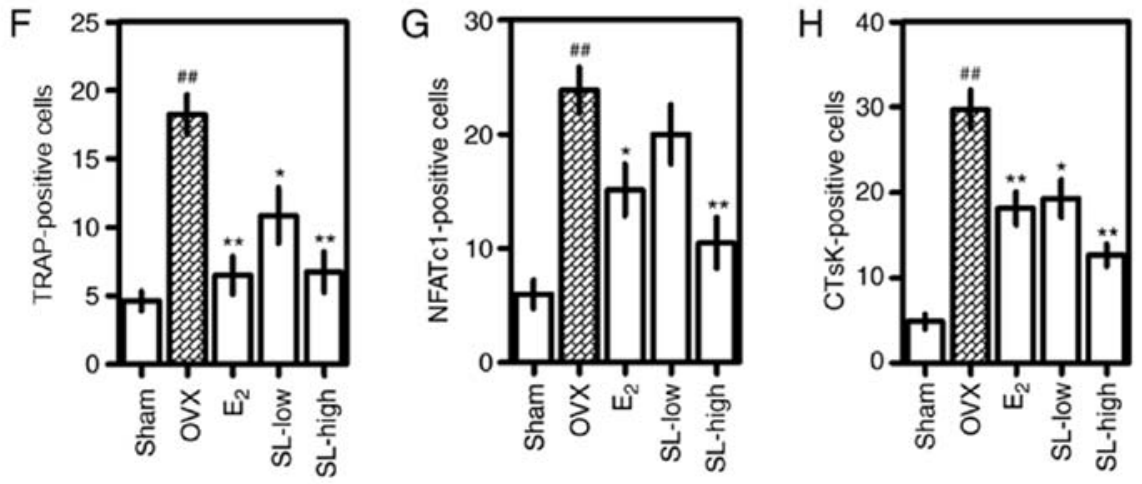

Figure 2. Effect of SL on histological changes in femoral tissue. (A) Decrease in the density of trabecular bone in the femoral tissue induced by OVX was analyzed by H\&E staining. (B) Number of osteoclasts in the femoral head was detected using a TRAP staining kit. TRAP-positive cells are marked with black arrows. (C) NFATc1 (green) and (D) CTsK (red) protein expression in the tissue was detected via IHC. All images were captured using a phase-contrast microscope. Magnification, x100; scale bar, $200 \mu \mathrm{m}$. (E) Trabecular area was measured using ImageJ. Number of (F) TRAP-, (G) NFATc1- and (H) CTsK-positive cells were counted. The results are expressed as the mean $\pm \mathrm{SEM}(\mathrm{n}=8) .{ }^{\# \#} \mathrm{P}<0.01$ vs. sham; ${ }^{*} \mathrm{P}<0.05,{ }^{* *} \mathrm{P}<0.01$ vs. OVX. OVX, ovariectomy; SL, Solanum nigrum Line; $\mathrm{E}_{2}, 17 \beta$-estradiol; H\&E, hematoxylin and eosin; TRAP, tartrate-resistant acid phosphatase; IHC, immunohistochemistry; NFATc1, nuclear factor-activated T cells c1; CTsK, cathepsin $\mathrm{K}$.

in the OVX group than in the sham group. The positive control group $\mathrm{E}_{2}$ exhibited a reduced decrease in bone density; the SL-low and -high groups also exhibited a suppressed decrease in bone density. As a result of analyzing the microstructure of the femur images using $\mathrm{CT}$ analyzer software, BMD and BV/TV were decreased due to OVX, and $\mathrm{E}_{2}$, SL-low and SL-high groups suppressed this reduction. The difference between the $\mathrm{E}_{2}$ and SL-high group was significant (Fig. 1B and C). In addition, Tb.N and Tb.Sp of the femur were decreased and increased by OVX, respectively. For Tb.N, $\mathrm{E}_{2}$, SL-low and SL-high groups were significantly different from the sham group; for Tb.Sp, $\mathrm{E}_{2}$ and SL-high were significantly different. These results indicated that the effect of SL on bone density recovery was comparable with that of the positive control group ( $\mathrm{E}_{2}$ treatment). Analyzing the TRAP activity in serum revealed that OVX did not significantly affect the expression of TRAP, but the SL-low and SL-high groups showed a notable ability to inhibit TRAP activity (Fig. 1F). The OVX group exhibited increased body weight and decreased uterine weight compared with the sham group. In addition, administration of $\mathrm{E}_{2}$ significantly suppressed this change and the SL-low and SL-high groups exhibited no effect on changes in weekly body and uterine weight (Fig. $1 \mathrm{G}$ and $\mathrm{H}$ ).

SL inhibits trabecular bone loss, osteoclast formation and expression of NFATcl and CTsK in femoral tissue. H\&E, TRAP and IHC staining were performed to observe histological and histochemical changes in the femoral head. The trabecular area of the femoral head was decreased following OVX; this was suppressed by administration of $E_{2}$ and SL-high (Fig. 2A and E). Measuring the area revealed a significant difference between the $\mathrm{E}_{2}$ and SL-high and OVX group. Consistent with the H\&E staining results, the number of osteoclasts in the femoral head was increased following OVX and decreased following treatment with $\mathrm{E}_{2}$, SL-low and SL-high (Fig. 2B and F). IHC staining was performed 
A

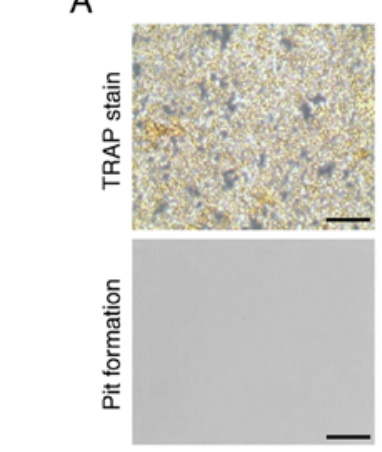

$\mathrm{SL}(\mu \mathrm{g} / \mathrm{ml})$
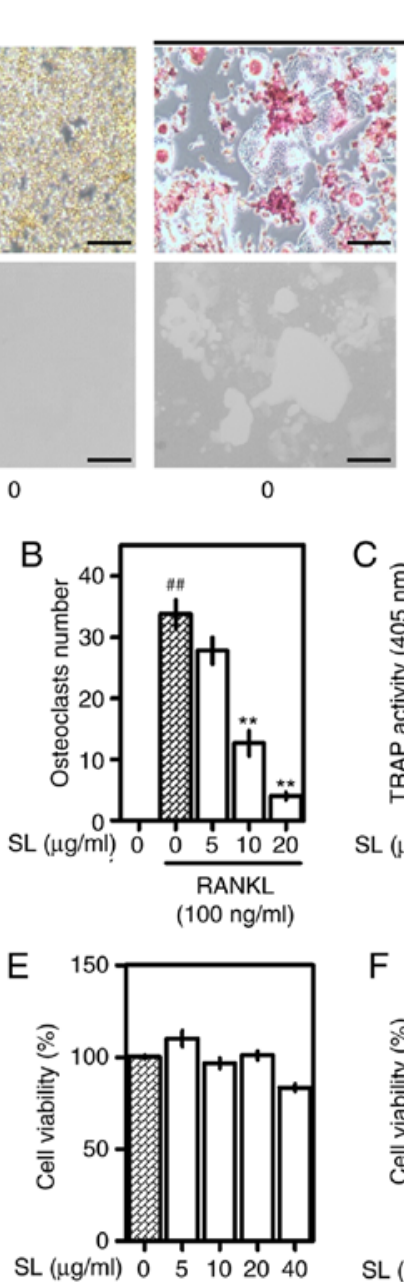

RANKL $100 \mathrm{ng} / \mathrm{ml}$
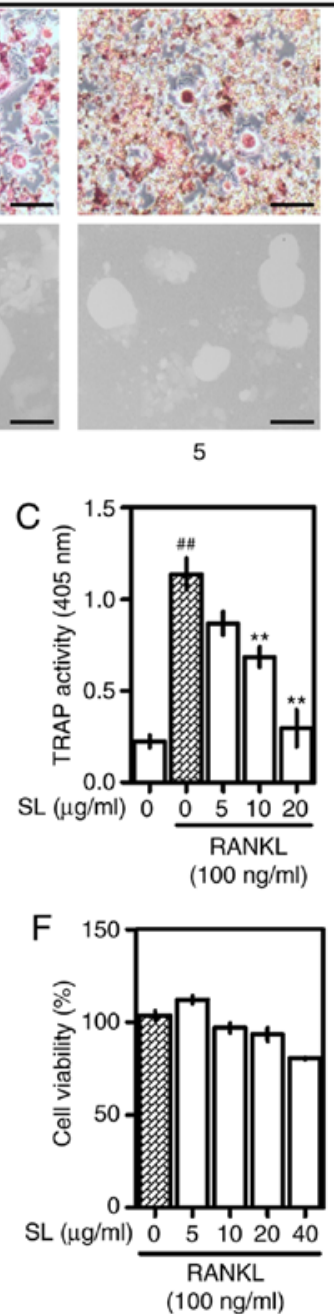

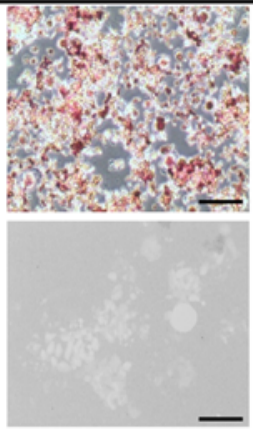

10
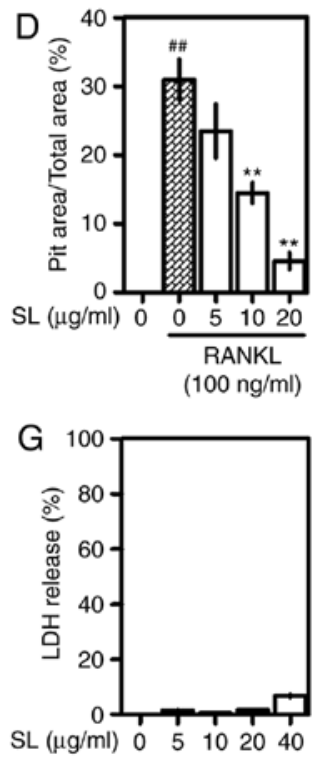

Figure 3. Effect of SL on osteoclast differentiation and bone absorption capacity. (A) Osteoclasts differentiated by RANKL stimulation were stained using TRAP. Osteoclast calcium absorption ability was measured using a pit formation plate. Images were captured using an optical microscope. Magnification, $\mathrm{x} 100$; scale bar, $200 \mu \mathrm{m}$. (B) TRAP-positive cells were counted. (C) Activity of TRAP in the medium was measured using the para-nitrophenyl phosphate method. (D) Absorbed area was measured using ImageJ. Cytotoxicity of SL on (E) RAW 264.7 cells and (F) osteclasts was verified via Cell Counting Kit-8. (G) Effect of SL on necrosis of RAW 264.7 cell was measured via LDH assay. The results are expressed as the mean \pm SEM ( $=3$ ). ${ }^{\# \# ~}<0.01$ vs. untreated; ${ }^{* *} \mathrm{P}<0.01$ vs. RANKL-alone. SL, Solanum nigrum Line; RANKL, receptor activator of nuclear factor- $\kappa \mathrm{B}$ ligand; TRAP, tartrate-resistant acid phosphatase; LDH, lactate dehydrogenase.

A
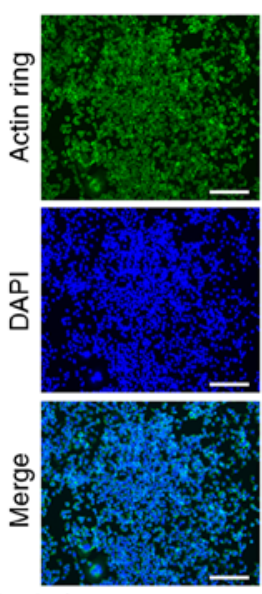

SL $(\mu g / m l)$
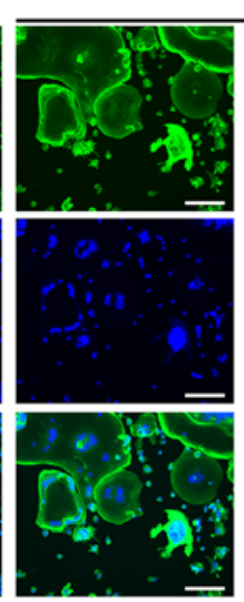

0
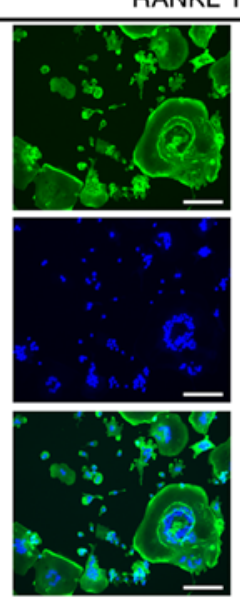

5

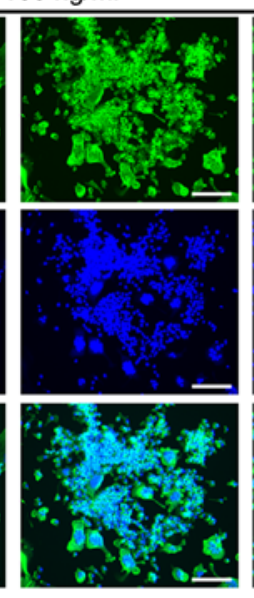

10
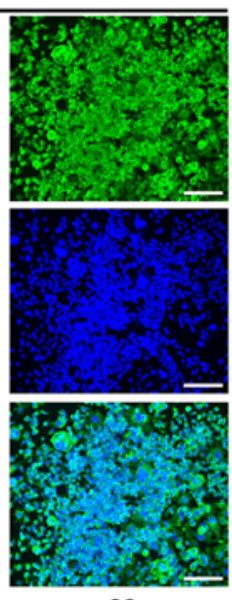

20
B

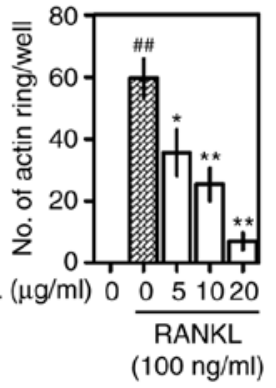

Figure 4. Effect of SL on formation of actin rings. (A) Formation of filamentous actin was detected with fluorescent phalloidin. (B) Formed actin rings were counted using an immunofluorescence microscope. Magnification, $\mathrm{x} 100$; scale bar, $200 \mu \mathrm{m}$. Results are expressed as the mean \pm SEM ( $=3$ ). ${ }^{\# \#} \mathrm{P}<0.01$ vs. untreated; ${ }^{\mathrm{P}}<0.05,{ }^{* *} \mathrm{P}<0.01$ vs. RANKL-alone. SL, Solanum nigrum Line; RANKL, receptor activator of nuclear factor- $\kappa \mathrm{B}$ ligand. 

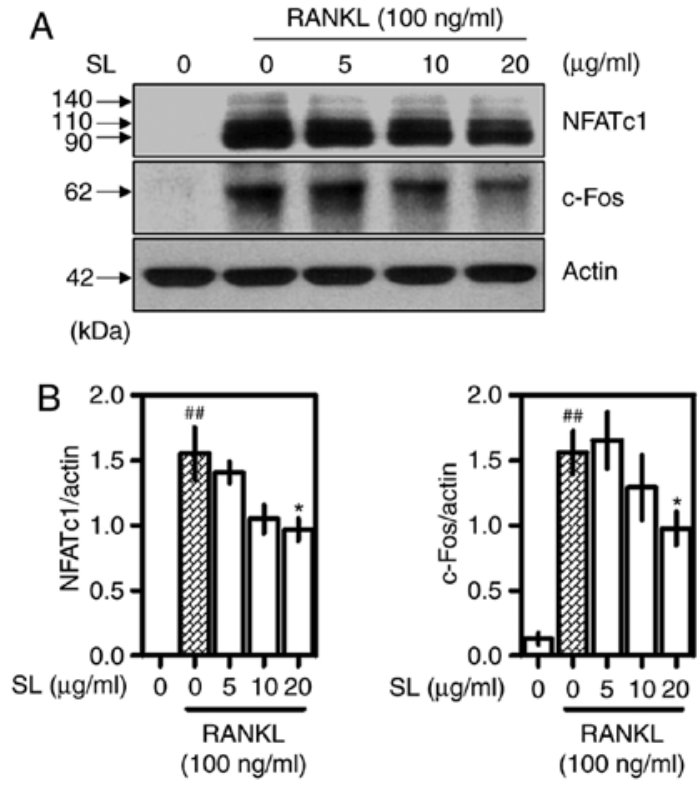
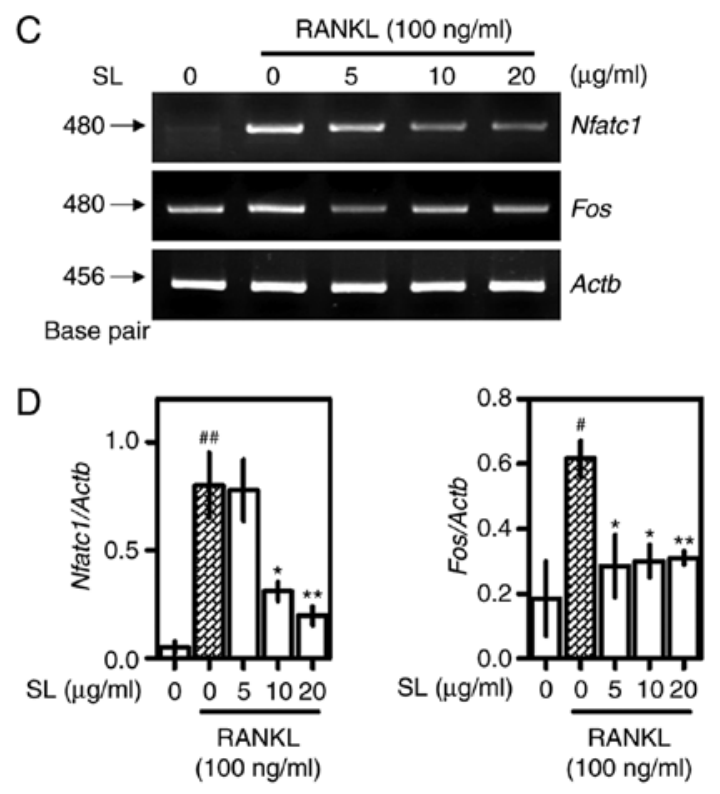

Figure 5. Effect of SL on expression of NFATc1 and c-Fos. (A) Protein expression of NFATc1 and c-Fos was verified by western blotting and (B) normalized to actin. (C) mRNA expression of NFATc1 and c-Fos was analyzed by reverse transcription-quantitative PCR and (D) normalized to actin. Data are expressed as the mean \pm SEM $(\mathrm{n}=3)$. ${ }^{\# \mathrm{P}}<0.05,{ }^{\# \#} \mathrm{P}<0.01$ vs. untreated cells; ${ }^{*} \mathrm{P}<0.05,{ }^{* *} \mathrm{P}<0.01$ vs. RANKL-alone. SL, Solanum nigrum Line; RANKL, receptor activator of NF- $\kappa$ B ligand; NFATc1, nuclear factor-activated T cells $\mathrm{cl}$.

to measure the protein expression of NFATc1 and CTsK in the femoral head. Expression of NFATc1 in the femoral head was increased in the OVX group compared with the sham group (Fig. 2C and G). Treatment with $\mathrm{E}_{2}$ inhibited this expression. In particular, the SL-high group notably inhibited expression of NFATc1 compared with the OVX group. Consistent with the NFATc1 staining results, the expression of CTsK in the femoral head was induced following OVX and decreased by $\mathrm{E}_{2}$ and SL (Fig. 2D and H).

SL inhibits osteoclast differentiation and bone absorption capacity. After confirming the positive effects of SL in the osteoporotic in vivo model, the effects of SL in the osteoclast model were confirmed using a RANKL-induced in vitro model. RAW 264.7 cells were cultured for 5 days in a medium containing RANKL (Fig. 3A). Differentiated osteoclasts were stained using the TRAP staining kit and multinucleated red giant cells were observed. SL decreased the area and number of TRAP-positive cells in a dose-dependent manner. In the pit formation assay, the absorbed area of the plate was used to measure the activity of osteoclasts. The absorbed area induced by RANKL treatment was decreased in cells treated with SL. Consistent with this, measuring the number of osteoclasts and TRAP activity in the medium demonstrated that SL inhibited osteoclast differentiation and activity (Fig. 3B and C). In addition, measuring the pit area formed by osteoclasts showed that SL also suppressed the absorbed area in a concentration-dependent manner (Fig. 3D). At $40 \mu \mathrm{g} / \mathrm{ml}$, SL decreased viability of RAW 264.7 cells and osteoclasts (Fig. 3E and F). Therefore, $40 \mu \mathrm{g} / \mathrm{ml}$ was considered toxic and subsequent cell experiments were performed using 0-20 $\mu \mathrm{g} / \mathrm{ml} \mathrm{SL}$. In addition, LDH was slightly increased following $40 \mu \mathrm{g} / \mathrm{ml} \mathrm{SL}$ treatment but was not detected at $0-20 \mu \mathrm{g} / \mathrm{ml} \mathrm{SL}$, indicating that $0-20 \mu \mathrm{g} / \mathrm{ml}$ SL did not induce necrosis (Fig. 3G).
SL suppresses formation of actin rings. The formation of an actin ring is an important target to measure bone absorption capacity via pit formation assay (25). The actin ring formation of osteoclasts treated with RANKL was observed via immunofluorescence analysis (Fig. 4). F-actin was observed in RANKL-treated RAW 264.7 cells, and the number of nuclei stained through DAPI decreased as cells fused during differentiation. SL treatment significantly decreased formation of F-actin in a concentration-dependent manner, which was consistent with the results of TRAP staining and pit formation assay.

SL inhibits expression of NFATcl and c-Fos. Western blotting and RT-qPCR were used confirm protein and gene expression of NFATc1 and c-Fos, which are important transcription factors for osteoclast differentiation (2). Following incubation for $24 \mathrm{~h}$ with RANKL and SL, proteins were extracted to confirm the effect of SL on expression of NFATc1 and c-Fos (Fig. 5A). These indicators were significantly inhibited when treated with $20 \mu \mathrm{g} / \mathrm{ml} \mathrm{SL}$ (Fig. 5B). mRNA expression was observed 4 days after RANKL and SL treatment (Fig. 5C). RANKL treatment upregulated expression of both indicators. SL showed inhibitory effects on NFATc1 expression levels at concentrations of 10 and $20 \mu \mathrm{g} / \mathrm{ml}$. In addition, Fos expression was inhibited at all concentrations of SL (Fig. 5D). Given the differences in sampling times between western blotting and RT-qPCR experiments, it was hypothesized that the inhibitor effect of SL on osteoclasts was exerted in the late, rather than the early, stage of differentiation.

SL suppresses expression of osteoclast-associated genes. The effects of SL on osteoclast-associated genes was demonstrated using RT-qPCR. Osteoclast-associated genes, such as Acp5 (TRAP), Tnfrsflla (RANK), Ctsk, Mmp9, osteoclast-associated immunoglobulin-like receptor (OSCAR, Oscar), ATPase $\mathrm{H}^{+}$ transporting V0 subunit d2 (ATP6v0d2, Atp6v0d2) and Ca2 

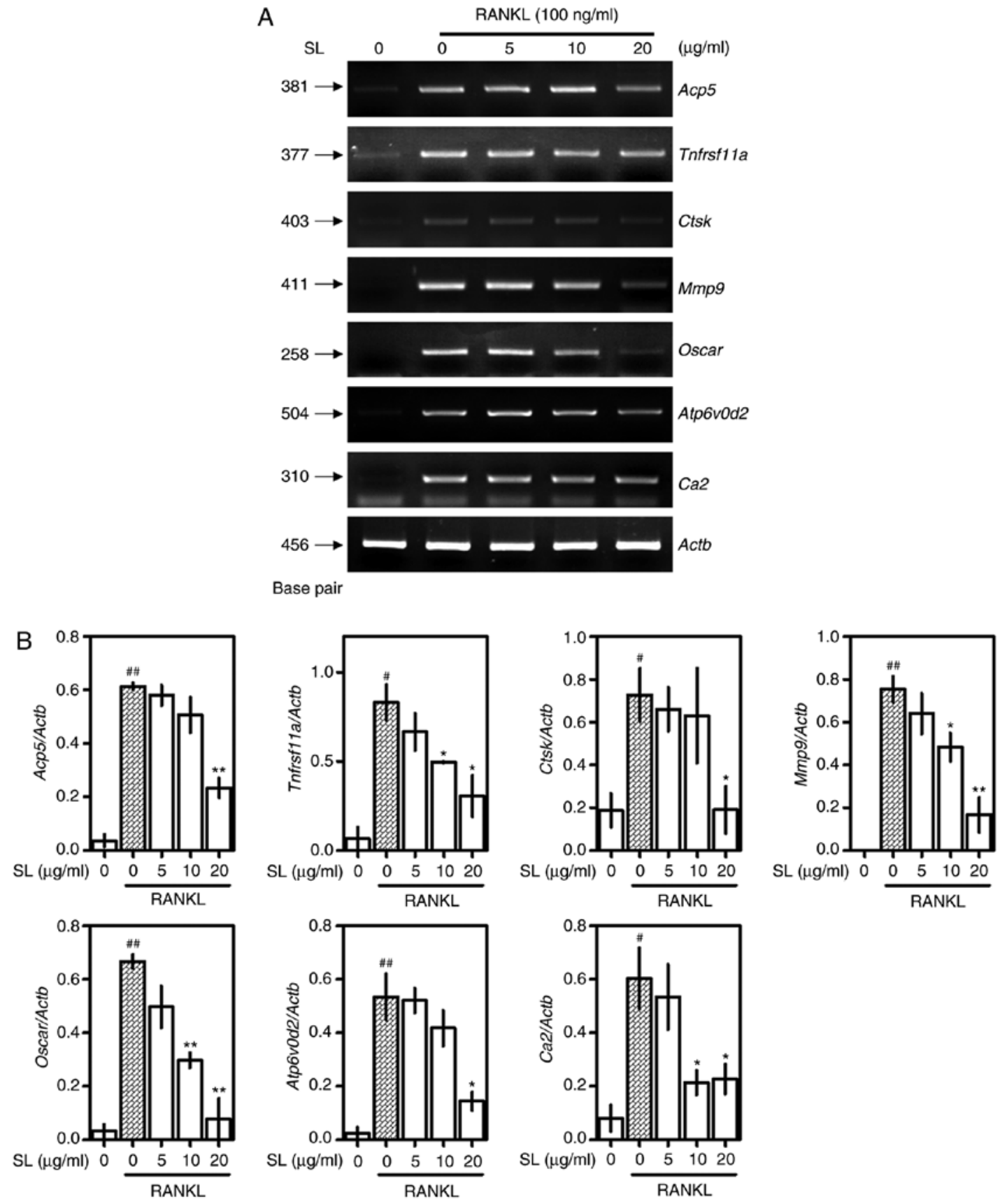

Figure 6. Effect of SL on expression of osteoclast-associated genes. (A) Inhibitory effects of SL on expression of osteoclast-associated mRNA was verified by reverse transcription-quantitative PCR and (B) normalized to Actb. The results are expressed as the mean \pm SEM ( $n=3) .{ }^{~} \mathrm{P}<0.05$, ${ }^{\# \#} \mathrm{P}<0.01 \mathrm{vs}$. untreated; ${ }^{*} \mathrm{P}<0.05$ and ${ }^{* *} \mathrm{P}<0.01$ vs. RANKL-alone. SL, Solanum nigrum Line; RANKL, receptor activator of NF-кB ligand; NFATc1, nuclear factor-activated T cells c1; Tnfrsf11a, receptor activator of NF-кB; Acp5, tartrate-resistant acid phosphatase; $C t s f k$, cathepsin K; Mmp9, matrix metallopeptidase 9; Oscar, osteoclast-associated immunoglobulin-like receptor; Atp6vOds, ATPase $\mathrm{H}^{+}$transporting V0 subunit d2; Ca2, carbonic anhydrase II; Actb, $\beta$-actin.

were increased by RANKL treatment; SL treatment decreased the expression of these genes (Fig. 6A). Normalized to Actb, Acp5, Ctsk and Atp6v0d2 were significantly suppressed following treatment with $20 \mu \mathrm{g} / \mathrm{ml}$ SL compared with the RANKL-alone group. In addition, Tnfrsf11a, Ca2, Mmp 9 and Oscar were significantly decreased when treated with 10 and $20 \mu \mathrm{g} / \mathrm{ml} \mathrm{SL} \mathrm{(Fig.} \mathrm{6B).}$

SL does not significantly affect osteoblast differentiation. After demonstrating the inhibitory effects of SL in an osteoclastogenesis in vitro model, the effects of SL in an osteoblast model were confirmed using a MC3T3-E1 cell model. SL did not significantly affect osteoblast differentiation and formation of calcified nodules. These results indicate that SL specifically acted on osteoclasts rather than osteoblasts (Fig. 7A and B). The concentration of SL did not affect the viability of MC3T3-E1 cells (Fig. 7C and D).

Quantitative analysis of SL. Chlorogenic acid, caffeic acid and quercetin are well-known active ingredients of SL $(23,24)$. The chromatography peak of ingredient standard is shown in Fig. 8A. In the SL Et-OH extract, peaks were observed from 0 to $50 \mathrm{~min}$ and each peak was detected at the same retention time (chlorogenic acid, 9.420; caffeic acid, 10.836; quercetin, $23.722 \mathrm{~min}$ ) as the ingredient standard (Fig. 8B). 
A
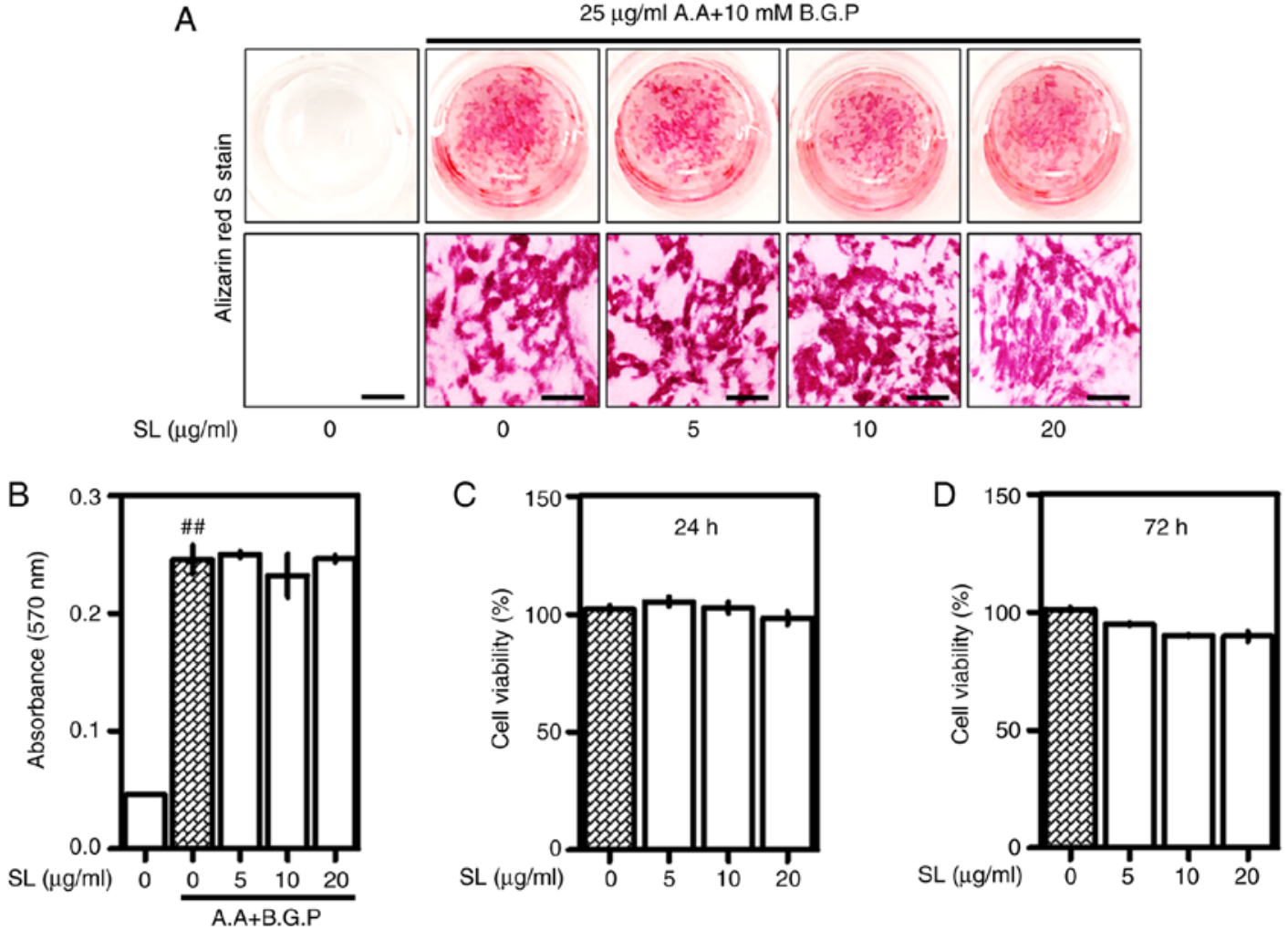

Figure 7. Effect of SL on osteoblast differentiation and calcified nodules. (A) Deposited calcified nodules were stained using alizarin red S. The differentiated osteoblasts were photographed with a camera and an optical microscope. Magnification, x100; scale bar, $200 \mu \mathrm{m}$. (B) Stained dye was extracted and measured at an absorbance of $405 \mathrm{~nm}$. Cytotoxicity of SL on MC3T3-E1 cell was verified via Cell Counting Kit-8 at (C) 24 and (D) $72 \mathrm{~h}$. The results are expressed as the mean \pm SEM $(n=3) .{ }^{\# \#} \mathrm{P}<0.01$ vs. untreated. SL, Solanum nigrum Line; A.A, ascorbic acid; B.G.P, $\beta$-glycerophosphate.
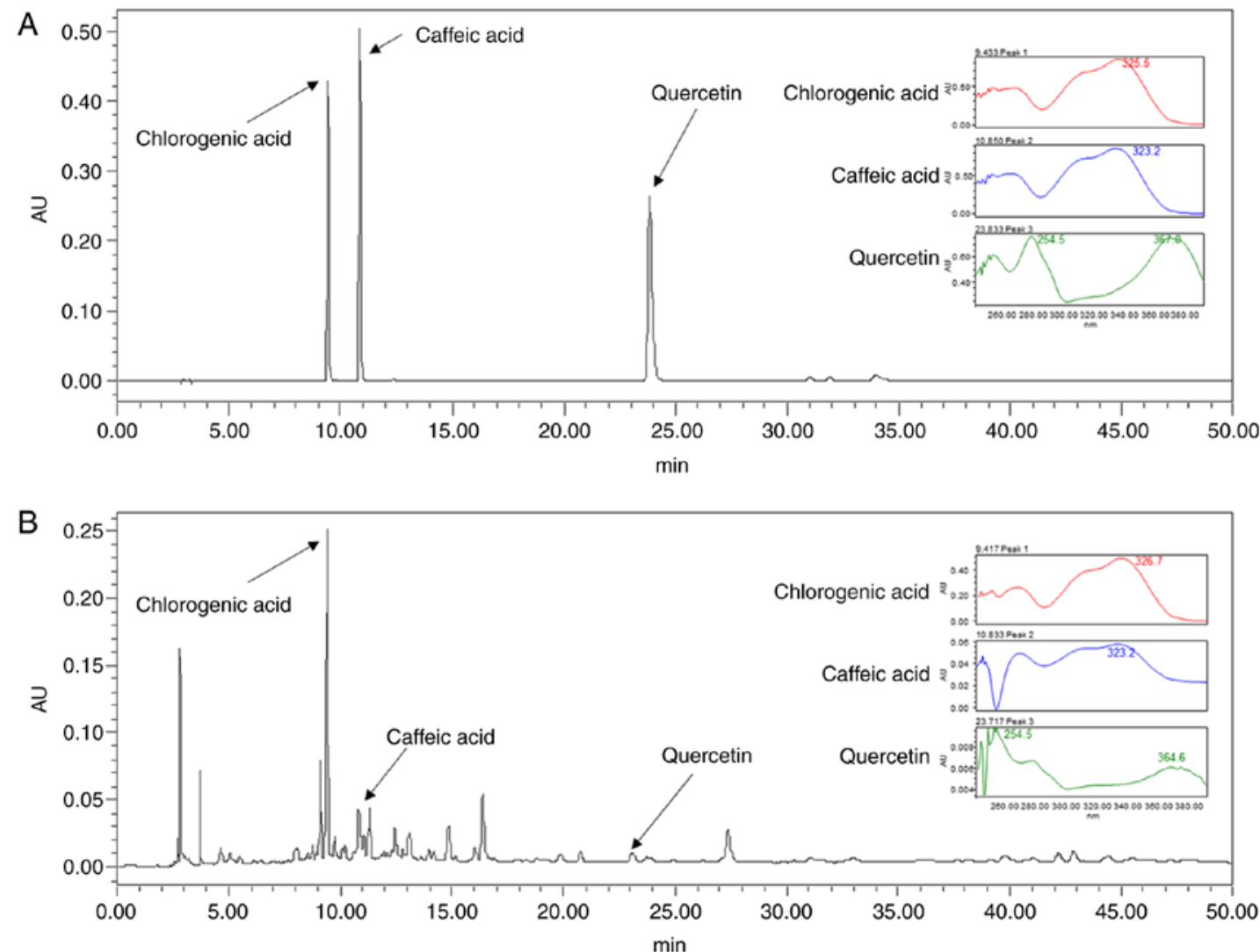

Figure 8. High-performance liquid chromatography analysis of SL and its ingredients. (A) Standard peaks of chlorogenic acid, caffeic acid and quercetin were detected at $280 \mathrm{~nm}$. Retention time, 9.439, 10.867 and $23.862 \mathrm{~min}$, respectively. (B) Ingredients were detected in SL. Retention time, $9.420,10.836$ and $23.722 \mathrm{~min}$, respectively. SL, Solanum nigrum Line. 


\section{Discussion}

In vivo, SL inhibited expression of NFATc1 and CTsK in the femoral head and significantly decreased bone density and osteoclast differentiation. In vitro, SL inhibited the expression of NFATc1/c-Fos during early and late osteoclast differentiation and suppressed expression of genes associated with differentiation and bone resorption. As a result, SL inhibited osteoclast differentiation, bone resorption activity and formation of actin rings.

Osteoporosis is characterized by a decrease in bone density and fragility. However, previous studies have shown that measuring bone volume and BMD is insufficient to determine improvement in osteoporosis, and that structural changes of trabecular bone must also be assessed (26,27). In the present study, the administration of SL in the OVX osteoporosis model not only increased BMD and bone volume, but also improved the trabecular bone microstructure. These results indicated that SL suppressed a decrease in bone density, which is a phenotype of osteoporosis, and improved bone quality via improved bone microstructure. The OVX-induced osteoporosis model shows the phenotype of postmenopausal osteoporosis and is used to research osteoporosis treatments $(28,29)$. Following OVX, an increase in body weight and a decrease in uterine weight due to hormonal changes are considered to indicate successful surgery (17). In the present study, the $\mathrm{E}_{2}$ group exhibited suppressed changes in body and uterine weight, whereas the SL group exhibited no effect. These results indicated that OVX surgery was successful and SL did not exert a hormone-associated effect similar to that of $\mathrm{E}_{2}(30)$.

RAW 264.7 cells are monocyte/macrophages extracted from male BALB/c mice and are used as a cell model for various pathological diseases, such as inflammation, antioxidant and osteoclast differentiation (31-34). When RAW 264.7 cells are treated with RANKL, which is a member of the TNF superfamily and a type of cytokine, the monocytes induce differentiation, fusion, function and maturation of osteoclasts (35). Osteoclasts express various phenotypic markers, the most representative of which is TRAP, as its concentration in serum is used as a biochemical indicator of osteoclast activity and bone resorption (36). In the present study, SL decreased serum levels and activity of TRAP and the number of TRAP-positive cells in the femur of OVX-induced osteoporotic rats and inhibited the differentiation of RANKL-induced TRAP-positive cells. These results suggested that the anti-osteoporotic effect of SL is mediated by suppression of osteoclast differentiation.

Osteoclast differentiation involves essential transcription factors such as NFATc1 (37). The importance of NFATc1 in osteoclast differentiation has been demonstrated in transgenic mice and cell models. Aliprantis et al (38) found that cells of NFATc1-deficient mice do not differentiate into osteoclasts, leading to osteopetrosis. The embryonic stem cells from which NFATc1 was removed from did not differentiate into osteoclasts, even following stimulation with RANKL, whereas embryonic stem cells overexpressing NFATc1 differentiate into osteoclasts without the need for stimulation with RANKL (39). In the present study, SL significantly inhibited the expression of NFATc1 in femoral tissue and RANKL-induced RAW 264.7 cells. These results indicated that the inhibitory effect of SL on osteoclast differentiation is mediated by NFATc1. In addition, NFATc1 regulates expression of various osteoclast differentiation and bone resorption factors, such as CTsK, MMP-9, OSCAR and ATP6v0d2 (40). CTsK and MMP-9 are expressed in mature osteoclasts attached to the bone surface and degrade the bone. According to Saftig et al (41), osteoclasts extracted from CTsK-knockout mice impair bone resorption. In the present study, SL suppressed expression of CTsK in femoral tissue and cell models of osteoclast differentiation. These results indicated that SL served an important role not only in inhibiting osteoclast differentiation, but also in suppressing its ability to absorb bone. OSCAR is expressed in preosteoclasts and mature osteoclasts and is an etiological factor in osteoporosis and rheumatoid arthritis (42). ATP6v0d2 serves an important role in cell-cell fusion and actin ring formation $(10,43)$. The actin ring is associated with the 'sealing zone' that is formed when osteoclasts attach to bone, which is a structural factor essential for osteoclast bone absorption (44). In the present study, SL inhibited the formation of actin rings and expression of ATP6v0d2, suggesting that SL controlled cell fusion during the early stages of osteoclast differentiation, as well as formation of the skeletal structure of the mature osteoclast.

c-Fos is a representative osteoclast transcription factor that controls expression of NFATc1 (40). c-Fos recruits the NFATc1 promoter in the early stages of osteoclast differentiation $(45,46)$. In addition, c-Fos-deficient cells cause disorders in NFATc1 expression and osteoclast differentiation via induction of RANKL, which is improved by overexpression of NFATc1 (46). c-Fos also controls expression of CA2, which serves an important role in osteoclast bone absorption function (47). CA2 acidifies the bone surface prior to osteoclast-mediated bone absorption, creating an environment in which various enzymes can function $(48,49)$. In the present study, SL inhibited both c-Fos and CA2 expression. These results showed that the inhibitory effect of SL on NFATc1 expression was mediated by regulation of c-Fos. In conclusion, it was confirmed that SL inhibited osteoclast differentiation and function by suppressing the expression of NFATc1/c-Fos, and thus, significantly suppressing OVX-induced decreases in bone density. These results highlight the possibility of SL as a therapeutic agent for management of osteoporosis.

The present study had certain limitations. The activity of osteoclasts was investigated via stimulation of RANKL. Various factors, such as inflammation, steroids and aging, cause osteoporosis (50-52). However, the effect of SL on these factors was not investigated in the present study. Research on treatment of osteoporosis research has focused on patients with postmenopausal osteoporosis (53). However, with an increase in the elderly population, male and senile osteoporosis is becoming increasingly important (54). Additionally, treatment with steroids results in potential social implications for patients due to adverse side effects (50). Therefore, studying the effect of SL on other osteoporosis-causing factors such as inflammation, steroids and aging may highlight more generalizable targets and mechanisms. Previous studies have shown that the fruit of SL contains solanine, which is known to be toxic (55-57). However, a previous study demonstrated that 
it displays hepatoprotective effects (58). Additional studies on the administration method and toxic concentration of SL are required. Expression of NFATc1 is controlled by MAPK, NF- $\kappa \mathrm{B}$ and c-Fos (2). However, only c-Fos expression was investigated in the present study. In order to confirm the anti-osteoporotic and inhibitory effects of SL on osteoclast differentiation, the effects of SL on phosphorylation of MAPK, ERK, JNK and p38 and expression of NF- $\kappa$ B induced by RANKL should be studied. The present study demonstrated the effect of SL on osteoclast differentiation but did not investigate the active ingredients in SL. In previous studies, SL has been shown to contain several active ingredients $(24,55)$, some of which have an effect on osteoclasts and osteoporosis. For example, diosgenin and ferulic acid inhibit differentiation of osteoclasts via $\mathrm{NF}-\kappa \mathrm{B}(59,60)$. According to $\mathrm{Wu}$ et al $(61)$, protocatechuic acid inhibits osteoclast differentiation via apoptosis of osteoclasts. In addition, Rutin inhibits osteoclast differentiation via its antioxidant effect (62). However, most of the components of SL have not been studied yet. Therefore, analysis of the structure and anti-osteoclastogenic effect of each component will be helpful in understanding the anti-osteoporosis mechanism of SL. It is necessary to verify the inhibitory effect of active ingredients in SL on osteoclasts in future.

\section{Acknowledgements}

Not applicable.

\section{Funding}

The present study was supported by the National Research Foundation of Korea grant funded by the Korean government (grantnos.2020R1A2C1007836and2020R1A6A3A01098984).

\section{Availability of data and materials}

All data generated or analyzed during this study are included in this published article.

\section{Authors' contributions}

YS and HSJ conceptualized the study. JHK and HS performed all experiments. JHK, MK and HSJ contributed to the statistical analysis. YS, SK and KS interpreted the results. JHK and HS drafted the manuscript. JHK and HS confirm the authenticity of all the raw data All authors read and approved the final manuscript.

\section{Ethics approval and consent to participate}

All animal experiments were approved by Kyunghee University Animal Committee [approval no. KHUASP(SE)-17-052].

\section{Patient consent for publication}

Not applicable.

\section{Competing interests}

The authors declare that they have no competing interests.

\section{References}

1. Sözen T, Özışık L and Başaran NC: An overview and management of osteoporosis. Eur J Rheumatol 4: 46-56, 2017.

2. Boyle WJ, Simonet WS and Lacey DL: Osteoclast differentiation and activation. Nature 423: 337-342, 2003.

3. Teitelbaum SL: Bone resorption by osteoclasts. Science 289: 1504-1508, 2000.

4. Tu KN, Lie JD, Wan CKV, Cameron M, Austel AG, Nguyen JK, Van K and Hyun D: Osteoporosis: A Review of Treatment Options. P\&T 43: 92-104, 2018.

5. Skjødt MK, Frost M and Abrahamsen B: Side effects of drugs for osteoporosis and metastatic bone disease. Br J Clin Pharmacol 85: 1063-1071, 2019.

6. Herbology Editorial Committee of Korean Medicine: Herbology. Younglimsa, Seoul 2004.

7. Youn YN, Lim E, Lee N, Kim YS, Koo MS and Choi SY: Screening of Korean medicinal plants for possible osteoclastogenesis effects in vitro. Genes Nutr 2: 375-380, 2008.

8. Ginaldi L, Di Benedetto MC and De Martinis M: Osteoporosis, inflammation and ageing. Immun Ageing 2: 14, 2005.

9. Souza PP and Lerner UH: The role of cytokines in inflammatory bone loss. Immunol Invest 42: 555-622, 2013.

10. Kim K, Lee SH, Ha Kim J, Choi Y and Kim N: NFATc1 induces osteoclast fusion via up-regulation of Atp6v0d2 and the dendritic cell-specific transmembrane protein (DC-STAMP). Mol Endocrinol 22: 176-185, 2008.

11. Kim M, Kim HS, Kim JH, Kim EY, Lee B, Lee SY, Jun JY, Kim MB, Sohn Y and Jung HS: Chaenomelis fructus inhibits osteoclast differentiation by suppressing NFATc1 expression and prevents ovariectomy-induced osteoporosis. BMC Complement Med Ther 20: 35, 2020.

12. Zakaria ZA, Gopalan HK, Zainal H, Mohd Pojan NH, Morsid NA, Aris A and Sulaiman MR: Antinociceptive, anti-inflammatory and antipyretic effects of Solanum nigrum chloroform extract in animal models. Yakugaku Zasshi 126: 1171-1178, 2006.

13. Zakaria ZA, Sulaiman MR, Morsid NA, Aris A, Zainal H, Pojan NH and Kumar GH: Antinociceptive, anti-inflammatory and antipyretic effects of Solanum nigrum aqueous extract in animal models. Methods Find Exp Clin Pharmacol 31: 81-88, 2009.

14. Miyamoto T and Suda T: Differentiation and function of osteoclasts. Keio J Med 52: 1-7, 2003.

15. Clohisy JC, Frazier E, Hirayama T and Abu-Amer Y: RANKL is an essential cytokine mediator of polymethylmethacrylate particle-induced osteoclastogenesis. J Orthop Res 21: 202-212, 2003.

16. Takayanagi H: The role of NFAT in osteoclast formation. Ann NY Acad Sci 1116: 227-237, 2007.

17. Kim JH, Kim EY, Lee B, Min JH, Song DU, Lim JM, Eom JW, Yeom M, Jung HS and Sohn Y: The effects of Lycii Radicis Cortex on RANKL-induced osteoclast differentiation and activation in RAW 264.7 cells. Int J Mol Med 37: 649-658, 2016.

18. Lee KY, Kim JH, Kim EY, Yeom M, Jung HS and Sohn Y: Water extract of Cnidii Rhizoma suppresses RANKL-induced osteoclastogenesis in RAW 264.7 cell by inhibiting NFATc1/c-Fos signaling and prevents ovariectomized bone loss in SD-rat. BMC Complement Altern Med 19: 207, 2019.

19. Yeom M, Kim EY, Kim JH, Jung HS and Sohn Y: High doses of Bupleurum falcatum partially prevents estrogen deficiency-induced bone loss with anti-osteoclastogenic activity due to enhanced iNOS/NO signaling. Front Pharmacol 9: 1314, 2018.

20. Tschöp MH, Speakman JR, Arch JR, Auwerx J, Brüning JC, Chan L, Eckel RH, Farese RV Jr, Galgani JE, Hambly C, et al: A guide to analysis of mouse energy metabolism. Nat Methods 9: 57-63, 2011.

21. Chan FK, Moriwaki K and De Rosa MJ: Detection of necrosis by release of lactate dehydrogenase activity. Methods Mol Biol 979: 65-70, 2013.

22. Hayman AR: Tartrate-resistant acid phosphatase (TRAP) and the osteoclast/immune cell dichotomy. Autoimmunity 41: 218-223, 2008.

23. Campisi A, Acquaviva R, Raciti G, Duro A, Rizzo M and Santagati NA: Antioxidant activities of Solanum Nigrum L. leaf extracts determined in in vitro cellular models. Foods 8: 8, 2019

24. Huang HC, Syu KY and Lin JK: Chemical composition of Solanum nigrum linn extract and induction of autophagy by leaf water extract and its major flavonoids in AU565 breast cancer cells. J Agric Food Chem 58: 8699-8708, 2010.

25. Matsubara T, Myoui A, Ikeda F, Hata K, Yoshikawa H, Nishimura R and Yoneda T: Critical role of cortactin in actin ring formation and osteoclastic bone resorption. J Bone Miner Metab 24: 368-372, 2006. 
26. Burstein AH, Reilly DT and Martens M: Aging of bone tissue: Mechanical properties. J Bone Joint Surg Am 58: 82-86, 1976.

27. Osterhoff G, Morgan EF, Shefelbine SJ, Karim L, McNamara LM and Augat P: Bone mechanical properties and changes with osteoporosis. Injury 47 (Suppl 2): S11-S20, 2016.

28. Kalu DN: The ovariectomized rat model of postmenopausal bone loss. Bone Miner 15: 175-191, 1991.

29. Kim EY, Kim JH, Kim M, Park JH, Sohn Y and Jung HS: Abeliophyllum distichum Nakai alleviates postmenopausal osteoporosis in ovariectomized rats and prevents RANKL-induced osteoclastogenesis in vitro. J Ethnopharmacol 257: 112828, 2020

30. Yousefzadeh N, Kashfi K, Jeddi S and Ghasemi A: Ovariectomized rat model of osteoporosis: A practical guide. EXCLI J 19: 89-107, 2020.

31. Taciak B, Białasek M, Braniewska A, Sas Z, Sawicka P, Kiraga Ł, Rygiel T and Król M: Evaluation of phenotypic and functional stability of RAW 264.7 cell line through serial passages. PLoS One 13: e0198943, 2018.

32. Funk JL, Feingold KR, Moser AH and Grunfeld C: Lipopolysaccharide stimulation of RAW 264.7 macrophages induces lipid accumulation and foam cell formation. Atherosclerosis 98 67-82, 1993.

33. Kong L, Smith W and Hao D: Overview of RAW264.7 for osteoclastogensis study: Phenotype and stimuli. J Cell Mol Med 23. 3077-3087, 2019

34. Yeom M, Kim JH, Min JH, Hwang MK, Jung HS and Sohn Y: Xanthii fructus inhibits inflammatory responses in LPS-stimulated RAW 264.7 macrophages through suppressing NF- $\kappa$ B and JNK/p38 MAPK. J Ethnopharmacol 176: 394-401, 2015.

35. Collin-Osdoby P and Osdoby P: RANKL-mediated osteoclast formation from murine RAW 264.7 cells. Methods Mol Biol 816 187-202, 2012.

36. Ballanti P, Minisola S, Pacitti MT, Scarnecchia L, Rosso R, Mazzuoli GF and Bonucci E: Tartrate-resistant acid phosphate activity as osteoclastic marker: Sensitivity of cytochemical assessment and serum assay in comparison with standardized osteoclast histomorphometry. Osteoporos Int 7: 39-43, 1997.

37. Kim JH and Kim N: Regulation of NFATc1 in osteoclast differentiation. J Bone Metab 21: 233-241, 2014.

38. Aliprantis AO, Ueki Y, Sulyanto R, Park A, Sigrist KS, Sharma SM, Ostrowski MC, Olsen BR and Glimcher LH: NFATc1 in mice represses osteoprotegerin during osteoclastogenesis and dissociates systemic osteopenia from inflammation in cherubism. J Clin Invest 118: 3775-3789, 2008.

39. Takayanagi H, Kim S, Koga T, Nishina H, Isshiki M, Yoshida H, Saiura A, Isobe M, Yokochi T, Inoue J, et al: Induction and activation of the transcription factor NFATc1 (NFAT2) integrate RANKL signaling in terminal differentiation of osteoclasts. Dev Cell 3: 889-901, 2002 .

40. Zhao Q, Wang X, Liu Y, He A and Jia R: NFATc1: Functions in osteoclasts. Int J Biochem Cell Biol 42: 576-579, 2010.

41. SaftigP,HunzikerE,WehmeyerO,JonesS,BoydeA,RommerskirchW, Moritz JD, Schu P and von Figura K: Impaired osteoclastic bone resorption leads to osteopetrosis in cathepsin-K-deficient mice. Proc Natl Acad Sci USA 95: 13453-13458, 1998.

42. Kim K, Kim JH, Lee J, Jin HM, Lee SH, Fisher DE, Kook H Kim KK, Choi Y and Kim N: Nuclear factor of activated T cells c1 induces osteoclast-associated receptor gene expression during tumornecrosis factor-related activation-induced cytokine-mediated osteoclastogenesis. J Biol Chem 280: 35209-35216, 2005.

43. Wu H, Xu G and Li YP: Atp6v0d2 is an essential component of the osteoclast-specific proton pump that mediates extracellular acidification in bone resorption. J Bone Miner Res 24: 871-885, 2009

44. Han G, Zuo J and Holliday LS: Specialized roles for actin in osteoclasts: Unanswered questions and therapeutic opportunities. Biomolecules 9: 9, 2019.

45. Anderson DM, Maraskovsky E, Billingsley WL, Dougall WC, Tometsko ME, Roux ER, Teepe MC, DuBose RF, Cosman D and Galibert L: A homologue of the TNF receptor and its ligand enhance T-cell growth and dendritic-cell function. Nature 390: 175-179, 1997.
46. Matsuo K, Galson DL, Zhao C, Peng L, Laplace C, Wang KZ, Bachler MA, Amano H, Aburatani $\mathrm{H}$, Ishikawa $\mathrm{H}$, et al: Nuclear factor of activated T-cells (NFAT) rescues osteoclastogenesis in precursors lacking c-Fos. J Biol Chem 279: 26475-26480, 2004.

47. David JP, Rincon M, Neff L, Horne WC and Baron R: Carbonic anhydrase II is an AP-1 target gene in osteoclasts. J Cell Physiol 188: 89-97, 2001

48. Kim M, Kim M, Kim JH, Hong S, Kim DH, Kim S, Kim EY, Jung HS and Sohn Y: Crataegus pinnatifida bunge inhibits RANKL-induced osteoclast differentiation in RAW 264.7 cells and prevents bone loss in an ovariectomized rat model. Evid Based Complement Alternat Med 2021: 5521562, 2021.

49. Lehenkari P, Hentunen TA, Laitala-Leinonen T, Tuukkanen J and Väänänen HK: Carbonic anhydrase II plays a major role in osteoclast differentiation and bone resorption by effecting the steady state intracellular $\mathrm{pH}$ and $\mathrm{Ca}^{2+}$. Exp Cell Res 242: 128-137, 1998.

50. Manolagas SC: Steroids and osteoporosis: The quest for mechanisms. J Clin Invest 123: 1919-1921, 2013.

51. Rochira V, Balestrieri A, Madeo B, Zirilli L, Granata AR and Carani C: Osteoporosis and male age-related hypogonadism: Role of sex steroids on bone (patho)physiology. Eur J Endocrinol 154: $175-185,2006$

52. Tella SH and Gallagher JC: Prevention and treatment of postmenopausal osteoporosis. J Steroid Biochem Mol Biol 142: 155-170, 2014.

53. Thulkar J and Singh S: Overview of research studies on osteoporosis in menopausal women since the last decade. J Midlife Health 6: 104-107, 2015.

54. Christensen K, Doblhammer G, Rau R and Vaupel JW: Ageing populations: The challenges ahead. Lancet 374: 1196-1208, 2009.

55. Gu XY, Shen XF, Wang L, Wu ZW, Li F, Chen B, Zhang GL and Wang MK: Bioactive steroidal alkaloids from the fruits of Solanum nigrum. Phytochemistry 147: 125-131, 2018.

56. Shen KH, Liao AC, Hung JH, Lee WJ, Hu KC, Lin PT, Liao RF and Chen PS: $\alpha$-Solanine inhibits invasion of human prostate cancer cell by suppressing epithelial-mesenchymal transition and MMPs expression. Molecules 19: 11896-11914, 2014.

57. Zhao L, Wang L, Di SN, Xu Q, Ren QC, Chen SZ, Huang N, Jia D and Shen XF: Steroidal alkaloid solanine A from Solanum nigrum Linn. exhibits anti-inflammatory activity in lipopolysaccharide/interferon $\gamma$-activated murine macrophages and animal models of inflammation. Biomed Pharmacother 105: 606-615, 2018.

58. Lin HM, Tseng HC, Wang CJ, Lin JJ, Lo CW and Chou FP: Hepatoprotective effects of Solanum nigrum Linn extract against $\mathrm{CCl}(4)$-induced oxidative damage in rats. Chem Biol Interact 171: 283-293, 2008.

59. Doss HM, Samarpita S, Ganesan R and Rasool M: Ferulic acid, a dietary polyphenol suppresses osteoclast differentiation and bone erosion via the inhibition of RANKL dependent NF- $\kappa \mathrm{B}$ signalling pathway. Life Sci 207: 284-295, 2018.

60. Shishodia S and Aggarwal BB: Diosgenin inhibits osteoclastogenesis, invasion, and proliferation through the downregulation of Akt, I kappa B kinase activation and NF-kappa B-regulated gene expression. Oncogene 25: 1463-1473, 2006.

61. Wu YX, Wu TY, Xu BB, Xu XY, Chen HG, Li XY and Wang G: Protocatechuic acid inhibits osteoclast differentiation and stimulates apoptosis in mature osteoclasts. Biomed Pharmacother 82: 399-405, 2016

62. Kyung TW, Lee JE, Shin HH and Choi HS: Rutin inhibits osteoclast formation by decreasing reactive oxygen species and TNF-alpha by inhibiting activation of NF-kappaB. Exp Mol Med 40: 52-58, 2008.

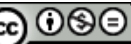

This work is licensed under a Creative Commons Attribution-NonCommercial-NoDerivatives 4.0 International (CC BY-NC-ND 4.0) License. 